\title{
Creative Computing and the Re-Configuration of Dance Ontology
}

\author{
Hetty Blades \\ King's College London \\ 1D Chesham Building \\ Strand, London. WC2R 2LS \\ hetty-rose.blades@kcl.ac.uk
}

\begin{abstract}
This paper assesses the impact of the Choreographic Language Agent and the Digital Dance Archives on dance ontology. Enhanced visualisation - afforded by digital technology - impacts on the essential ontological features of dance, such as ephememerality and the human body. Referring to the work of Nelson Goodman (1968) and Martin Heidegger (1977), I discuss the significance of creative programming for dance, asking what such tools reveal about the ontology of the form and existing concepts of movement, notation and embodiment.
\end{abstract}

Dance Ontology Digital Reveal Embody

\section{INTRODUCTION}

The relationship between dance and computers is complex: whilst computers provide informative and useful tools for the creation, experience and documentation of dance, they also contain features that are in direct contradiction to the essence of the form. Technology - with its dismissal of the body, its permanence and its repetitious nature, is a phenomenon in polar opposite to the ephemeral, fleshy experience of human movement. However, the two are increasingly interacting in choreography, performance and documentation. In fact, some level of technological involvement is commonplace in the production of every work. Throughout history, technology has always been involved in the creation of dance works - not only by providing lighting and music, but also allowing for the recording of dances - which is by no means a new phenomenon. In recent years we have seen dance practitioners using computers in increasingly creative ways. New technologies are frequently used in live performance. Projections, time delay and immersive technologies are being adopted by mainstream companies such as The Royal Ballet (2012), as well as experimental performance practitioners like Stelarc (1980 - 2012). Each new way that dance and technology interact impacts on the nature of the form. By considering this impact, we are able to discover essential characteristics of dance. Technology simultaneously changes and reveals the dance's ontology. I will consider this affect on dance as an action associated with movement, and on the nature of the dance 'work'.
In A Question Concerning Technology (1977), Martin Heidegger suggests the "the essence of technology is by no means anything technological" $\mathrm{He}$ claims that technology is neither merely a means to an end, nor a simply human activity, but rather "a means and a human activity".. He suggests that technology reveals something about humans, therefore the 'essence' he refers to is human, as opposed to technological. With this in mind, I will examine tools developed in order to visualise certain characteristics of dance; and analyse the ontological characteristics that such systems reveal. Heidegger claims that "[i]nstrumentality is considered to be the fundamental characteristic of technology" (Heidegger 1977); however deeper enquiry into technology suggests that "[i]he possibility of all productive manufacturing lies in revealing" (Heidegger 1977) I intend to ask; what do visualisation tools, designed for instrumentality in fact reveal? By assessing the impact of this software on dance ontology, we are forced to examine its perceived ontological features. Characteristics of movement previously considered crucial to ontology are challenged by new technology. For example, I will assess the role of the body in the act of embodiment. The term 'embody' is used in dance discourses to describe the act of internalising a given stimulus, or meaning 'in the body'. Embodiment and dance is widely discussed (Laban \& Ullman 1950, Klemola 1991, Sheets-Johnstone 2011, Block and Kissell 2001), with general usage concerning a certain being-ness with and of the body. I will consider the possibility of non-bodily embodiment, asking if computers can 
embody movement. The term is defined broadly in the Concise Oxford English Dictionary (2008) as to, "give tangible or visible form of an idea or quality". This makes no mention of the body, suggesting that the body is not definitively crucial to the term. If the body is not required for embodiment, and electronic visualisations are able to embody movement, the ontological significance of the body in choreography is called into question.

The aim of this paper is to assess the ontological impact of computer programs designed to make visual (or 'reveal') certain components of dance movement and performance. I will concentrate on two examples of computer programs developed in 2011, specifically for dance. Initially I will consider the Choreographic Language Agent (CLA), before considering how the issues raised by this system relate to the philosophical problems posed by the Digital Dance Archives (DDA).

\section{ONTOLOGY AND DOCUMENTATION}

For many reasons dance is a complicated art-form to discuss. Traditionally it exists only in the moment of performance. Unlike plays and musical works, dance works generally possess no text or score. Without permanent material presence, works are reliant upon human enactment in order to physically exist. Therefore the form possesses complex existential characteristics. Whether or not works exist outside of instantiation is a problematic issue. Whilst they don't exist physically when they are not being performed, we are able to remember, discuss and re-stage works. Therefore they continue to exist in an abstract form. Reliance upon human instantiation means that they are only ever physically present temporarily, unlike paintings, sculptures, and even plays (which have material texts to which we can permanently refer). The ephemeral nature of dance is considered to be crucial to the form (McFee 1992, Phelan 1993), yet it provides problems when it comes to discussing and analysing dance, as we have no physical object to refer to. Therefore the documentation of dance through recording, photographs and written notes has always been important. However documentation creates philosophical problems. Graham McFee claims that "the work of art is encountered only when one attends a performance, for only then is the work instantiated. In particular, one is not confronted with a work of art when one confronts only a notated score or a film or video" (1992). However; if only a live performance can be a true token of the work, what are documentations? And how do they relate to the abstract work?

The evolution of technology is affecting documentation and creation. It is increasingly easy to record footage. We are also now able to see many more details through $\mathrm{HD}$ technology and multi-camera filming. The World Wide Web also provides a vast arena for sharing and storing recordings and other documentations, meaning that accessibility to works has been revolutionised. We can now see almost any work whenever we want, without having to attend a theatre, or visit an archive. Technology is also being used by many choreographers as a key component to works, with artists such as Sarah Rubidge dedicating their careers to experimenting with technologies in live performance. Software is also being developed for use in the studio. Digital technology and the Internet allows for the creation of multiple types of performance artifacts. The electronic images created and stored by computers possess ontological significance. They provide access to the work, albeit through a different mode to the live performance.

Creating and using dance specific software is also not a new phenomenon - as long ago as 1986 Merce Cunningham was developing and working with Life Forms (Schiphorst 1986). This program allowed Cunningham to create movement on a computer, using representations of bodies. William Forsythe, amongst others, has also used innovative programming to visualise the structures of his choreography (Forsythe 2009). Each approach tells us something about the essence of dance. By analysing the priorities of the programs, and the visualisations created, ontological details become apparent; further enhancing our understanding of this complex form.

The CLA was developed in 2011 by choreographer Wayne McGregor of Random Dance and the OpenEndedGroup, Mark Downie (OEG), Nick Rothwell (CASSIEL), Alan Blackwell and Luke Church. This program was built using Field software, developed specifically for digital art (Open Ended Group 2012). The CLA was developed as part of a larger project that aimed to understand the mental and physical processes involved in choreography and to use this understanding to develop software that is able to aid and augment the creative process (DeLahunta, 2009). The system is intended to serve as an "extended interactive notebook" (2009). DeLahunta suggests that the choreographer's notebook is employed as "a toolkit for selfreflection/examination, for the collective documenting and sharing of creative ideas, scripts and scores, capturing the dynamics of gesture and recording notes for future reference." (DeLaHunta et al 2004). The program allows the choreographer to explore visualisations of shapes, structures and directions on a screen; these sketches are then animated by the program and act as a stimulus for movement. The images created are abstract, as opposed to avatars or human figures. Many 
questions are raised by this program; its active role in the choreographic process presents an altered mode of production for dance. Furthermore, documentation of the creative and cognitive process potentially creates a new form of score. I will analyse the documentation produced with the CLA in relation to Nelson Goodman's discussions (1976), of scores and notational systems, in order to assess whether or not we can consider the documentation created to be a score, and how the artifact relates to the final work.

The creation of an electronic score was one of the motivations for Cunningham in the development of Life Forms. As long ago as 1968 he was hoping to develop "an electronic notation...that is threedimensional" (Cunningham, 1980). Notation has huge benefits in terms of documenting details, and Cunningham envisaged a program that would allow him to create his work through a computer, cataloguing every feature, and generating a detailed record. Dance does not have a widely used notational system. Whilst there have been notational languages developed such as Laban and Benesh notation, these are used only in specific environments. They require specialised training, meaning that companies must employ experts in order to document or re-stage works. This is timeconsuming and costly, and therefore not common practice outside of classical ballet, or specific historical projects. The ease of video recording also potentially hindered the development of these notations, as choreographers are able to document movement for memory and archiving in a fast and cost-effective manner.

Life Forms introduced the computer as an active agent in the choreographic process. This is an important ontological shift. Both Life Forms and the CLA play active roles in the development of movement, albeit in different ways. The manner in which movement is generated on a screen, and enacted by dancers raises questions about the nature of embodiment. This approach is in direct contradiction with other widely used choreographic methods. Contemporary dance choreography often relies heavily on improvisation, usually working with an idea or set of rules, choreographers often encourage an approach that is unconcerned with shape, but rather explores what the body creates in response to a stimulus. This approach has developed from the choreographic models and theories created by Rudolph Laban at the start of the $20^{\text {th }}$ Century. One of the main concerns of Laban's approach was 'effort', which he describes as "the inner impulses from which movement originates" (in Block \& Kissell, 2001). If these inner impulses are not manifested straight to movement but documented and used as a stimulus, a different mode of creation occurs. This is potentially the same as the process of writing in a notebook, and using the notes to inspire movement. However, the limitations of the language available on the CLA, and the way in which the program animates the images means that the computer controls the outcome, and is therefore autonomous in a way that the notebook is not.

The nature of embodiment is also important in the analysis of my second example: The Digital Dance Archives (DDA) are the result of an AHRC funded collaboration between the University of Surrey and Coventry University. It offers new ways to search for documentations, such as films and photographs. The archives exist online and are available to the public. The documentation of dance challenges the form's identifying feature of ephemerality. This issue is particularly relevant as we increasingly watch dance online. Watching performances on the Internet challenges the ontological significance of 'liveness' endorsed by McFee. The temporality of performance is replaced by the potential for eternal replication through a screen. But does this provide access to the 'work'? This poses the question: If we have only seen a recording of a performance, can we claim to have seen the work? Peggy Phelan suggests that performance cannot be documented, and that if it is it becomes something other than performance (Phelan 1993). However Philip Auslander, claims that films of live works can be considered performances. This is due to the fact that they also exist physically only in the moment of enactment, and are therefore as significantly ephemeral as live performance (Auslander 2008). This affects the way in which we consider the relationship between the film and the work, and undermines the importance of live performance as a fundamental feature of dance.

However, it is the specificities of the archive search functions that are of particular interest in this paper. The user is able to select a shape from an image; the program will then search the archive for similar shapes. This way of relating to dance, postperformance, reveals the significance of shape and further challenges the status of live instantiation as the primary mode of existence for dance. Furthermore, archived footage and images provide a practical use in the identification and re-staging of works, meaning that they fulfill some of the functions of a score.

\subsection{The choreographic language agent}

The CLA comprises two screens and a spherical mouse, which senses the movement of the hand in three-dimensions. The process starts with the user communicating choreographic ideas by inputting words and diagrams, which appear on the righthand screen. The user forms a "sentence written in a language known to this tool."(Downie, 2009). The 
agent then uses this sentence to form an animation. The movement is visualised by the agent. It works by animating the specific points that constitute the dancer's body parts and correspond to points in space, as well as the dancer's kinesphere (Downie, 2009). The visualisation makes no explicit reference to the human body.

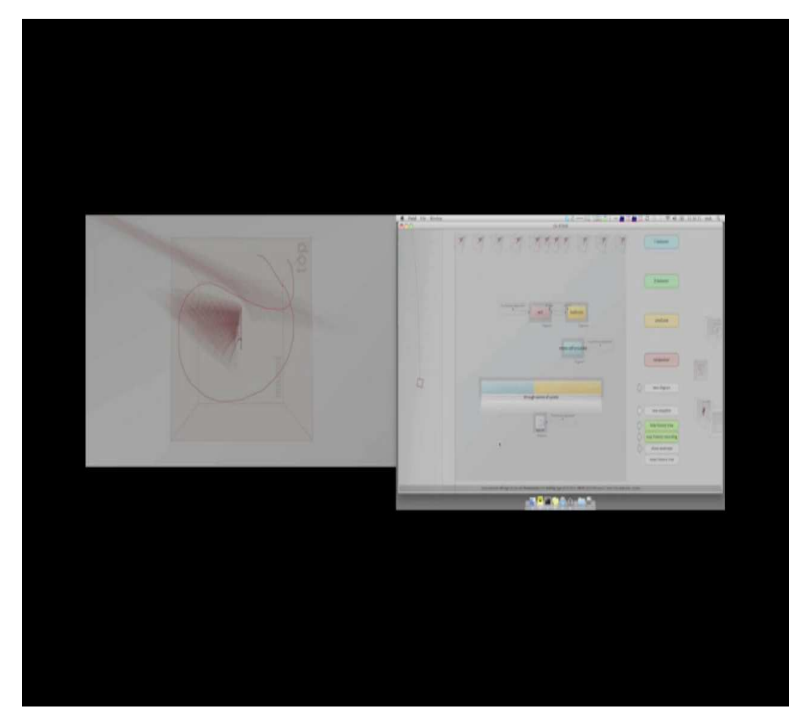

Figure 1:: The Choreographic Language Agent animating a diagram

The CLA is certainly not the first or only example of software created specifically for dance; however it does present some unique ontological queries. Other experimentations with software have had different motivations and outcomes. For example Life Forms functions by creating choreography on human avatars which is then learned by dancers. This means that the movement is visualised on the body from the start of the process. Forsythe's Synchronous Objects for One Flat Thing Reproduced (Forsythe 2009), aims to reveal "the interlocking systems of organization in William Forsythe's choreography. This tool applies visualisation techniques to existing choreography, as opposed to actively contributing to material. It provides a form of documentation, as opposed to aiding creation. Each choreographer and programmer have specific interests in the role that computers can play in choreography, therefore the systems are often as idiosyncratic as the choreography. Steve Dixon points out that; "The development of original software and hardware systems by dance artists has been somewhat fragmentary and individual, in many ways reflecting the development of the dance and technology movement itself" (Dixon 2007). This is an important thing to consider when discussing ontology; we need to remember that individuality and subjectivity are active components in creativity. Although dance arguably possesses universal properties, such as movement, the way in which practitioners use digital technology to record, create and perform such properties are vast and varied. This means that each context poses an idiosyncratic challenge to dance ontology. Whilst a particular way of using software may impact on the development of movement, it does not necessarily create repercussions beyond the context it exists in. For example, the CLA doesn't necessarily change the nature of movement universally, rather it tells us something about the about movement generated using the tool.

The use of the CLA raises some interesting queries regarding the creative process, in particular the creation of the art works. It raises the questions; at what point does a work start to exist? The point of creation is an ongoing ontological discussion (Levinson 1990 \& Lamarque 2010). For example does a dance work exist prior to the premiere? If a work must be completed and 'signed off' through public instantiation, what do dancers rehearse? The work is envisaged, formed, rehearsed and discussed prior to performance. Therefore, the work exists - potentially just as significantly as it does once it is made public - albeit in an unfinished form. Many philosophers have tried to resolve this problem for various art-forms. Some scholars, such as Jerrold Levinson (1990) suggest that multiple art-forms such as musical and dance works exist as permanent abstract structures, which are then 'discovered' by composers or choreographers. Another suggestion, from R.G. Collingwood is that works of art come into existence in the imagination of the artist. He claims that "a work of art may be completely created when it has been created as a thing whose only place is in the artist's mind." (Collingwood 1958). He uses the example of a tune, claiming that when a man makes up a tune, he may hum it, he may write it down, or he may play it on an instrument, he may even do these things in public. But, he claims, "these things are accessories of the real work", and that "The actual making of the tune is something that goes on in his head, and nowhere else" (1958). If this is the case and the work comes into existence in the choreographer's imagination, the images generated on the CLA are the first physical token of the work, as opposed to a by-product of the act of discovery. Whilst the document created is only an accessory, in Collingwood's terms, it allows us to visualise cognition, bringing the significance of the artist's imagination to the forefront of the work's identity. Furthermore, if the work of art exists as soon as it is formed in the choreographer's imagination, the significance of human enactment is called into question.

Whilst McFee suggests that we can only encounter a work through physical performance, Collingwood says a work does not need to take any physical form in order to exist. The CLA however, allows the work to have physical form without human 
performance. But, can we really consider computer images, to be a dance work? It is problematic to suggest that these things are as much the work as a performance. However, this way of understanding the creation of dance highlights their complex ontology. If we can consider these images to be a work, therefore suggesting that computers are able to quantify the ontological properties of dance, the impact on the concept of dance is vast. Outside of instantiation works exist purely as mental entities, therefore it is potentially appropriate to consider them to be created as such. If we are to go down this route of enquiry, the CLA can be viewed as generating a text, or score from which the performance is made. Like the creation of a play or musical work the transition from imagination to instantiation is mediated through a physical object. Traditional Laban notation scores are created alongside the work, or once it has been finished. Notators attend rehearsals and performances in order to document the details of the movement. The CLA therefore offers a different form of score, as it not only exists first, but dictates the development of the work.

Mark Downie suggests that the program creates "a new form of dance notation - one which aids the choreographer in generating dance movements rather than in recording existing movements" (2009). But can this abstract document really be considered a score, correlating to both work and performance? Nelson Goodman states that a score "has as its primary function the authoritative identification of a work from performance to performance" (Goodman 1976). There is no requirement that a notation is able to be read and understood by everyone, musical scores only serve to identify works by those able to read music. Similarly Laban notation is only readable by a few professionals, yet still serves as an identifying score. So when Goodman claims that it must serve to identify a work, he does not mean that it must share recognizable aesthetic features. Therefore, even if only one person (the one who created the images and subsequently the work), is able to use the documentation to establish whether or not a certain set of movements is indeed a performance of a specific work, it may serve as a form of score. However, scores rely on formal notation systems. Goodman points out that:

Scores and performances must be so related that in every chain where each step is either from score to compliant performance or from performance to covering score or from one copy of a score to another correct copy of it, all performances belong to the same work and all copies of scores define the same class of performances. (Goodman 1976)
This stringent relationship between the CLA animation and the resulting performance seems unlikely. The nature of the system means that subjective interpretation plays an important role in the creative process. The animations are interpreted by the choreographer or dancers. This movement then becomes the performance. Once this has occurred, the people involved would theoretically be able to determine, through analysing the sketches whether they represented one work or another. However, this would be reliant upon the recollection of the act of interpretation, and decoding the creative process that led from the sketch to the movement- as opposed to reading a codified notational system.

Goodman points out that "not every symbol system with a notational scheme is a notational system" (Goodman 1976), but can we consider CLA as a notational system? A key part of Goodman's distinction lies in the nature of the characters used, he claims that "[a] necessary condition for a notation, then, is character indifference [Goodman's emphasis] among the instances of each character" (Goodman 1976). I.e. no one mark can belong to more than one character. This is problematic in the case of the CLA; the notation consists of various lines. These lines are developed in relation to specific body parts and points in space, so theoretically they should be able to be 'read' as corresponding mathematically and anatomically to movement. However, this is not how the program is used. The sketch feature, and the way in which the movement is developed from the images mean that these lines do not directly correlate to the movement that results from them. In Goodman's terms then, this is not notation. It is simultaneously a representation of the process of creation, and documentation of it. In this way it is similar to a recording, but it documents process rather than product, this is the diametric opposite of Laban notation, which documents the final outcome. The images do not function in the traditional sense of a score, they are not created for the purpose of identification - such a feature would be incidental, rather than defining. Furthermore, a traditional score is reliant upon the occurrence of human movement, whereas this documentation serves to invoke such activity. What then are these images? Perhaps we can dismiss them off as a remnant of a necessary activity, to generate the significant object (the performance). However they do possess ontological importance. The physical, visual manifestation of the act of creation offers a new form of existence for a work, prior to human embodiment.

Whilst traditionally we have understood dance works to be exemplified by performances, this tool demonstrates an ontological quandary. For example, if a work is developed using the CLA, the 
sketches are created, the movement created and rehearsed but for some reason, never gets performed in public; has the work ever existed? This seems unlikely. Whilst we are used to the notion that the performance is the work, we cannot dismiss the relationship between these diagrams and the work. In the same way that the dancer is a crucial entity, this program is a fundamental component to the work, and therefore the performance. In fact it is the first embodiment of the work. If we are able to consider the work as existing before instantiation, these animated structures are ontologically crucial to the work. This calls into question the primary significance of the human body. The work is 'embodied' by the computer, in that sense that the idea of the work is given visible form, without the need for human movement.

So, what does this tool reveal to us about the ontology of movement and the nature of embodiment? It is possible to suggest that the CLA exposes the significance of geometry and shape, implicating these features as defining ontological characteristics of movement (which a universal property of dance). The way, in which the tool functions as a stimulus, creating a shape which is then explored physically- contrasts to other choreographic approaches and tools, which aim to create movement from internal stimulus.

This implies that dance possesses characteristics which are distinct from the human body. The shapes generated show us how movement is perceived and created in the mind of the choreographer and by the computer. The fact that they are not represented on a body, suggests that the 'essence' of the movement is not reliant on human embodiment. The human body is the final part of the production process, as opposed to the primary feature. The involvement of the computer reveals this by creating a visual and physical exemplar of the transition from thought to movement. However, it is also possible to suggest that the images are only representative of a prescribed outgoing, and the programme dictates the outcome. The autonomy of the machine sets it apart from a notebook. The system mediates the process. Unlike a video camera or Laban notation score, the CLA does not create records of existing movement but effects the movement through the language available.

\subsection{The Digital Dance Archives}

This ontological significance of shape is further revealed in examination of the Digital Dance Archives (DDA). The DDA are the result of one of many projects currently looking at creative ways to document and archive dance digitally. It is home to six collections, spanning over 100 years of British dance. It contains videos and images, including drawings from Laban's archives. The archive allows users to create their own scrapbooks, tag and annotate sources, and search across the collection by selecting a colour or shape and looking for similar images. The 'Pose' search mechanism is of particular interest. Users can use the mouse to highlight part of an image and the search engine will return images which resemble the selected shape.

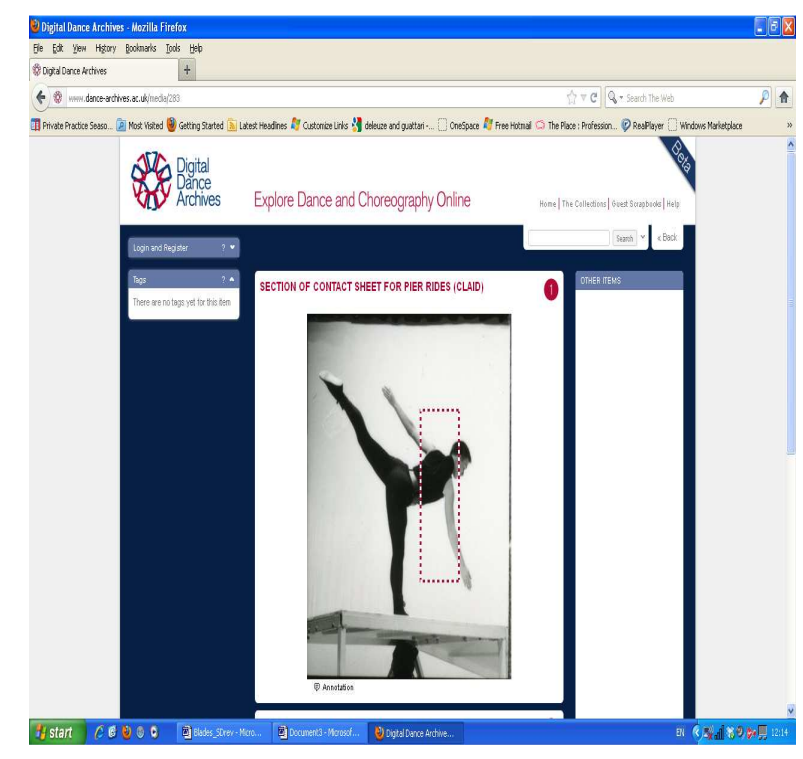

Figure 2:: Selecting a shape for 'Pose' search on the Digital Dance Archives

The sources returned are often stylistically very different to the original image used. Furthermore, the diagrammatic sketches from Laban's archive often appear in response to a 'Pose' search. The inclusion of these drawings in the archive demonstrates the historical and ontological significance of creative products, aside from performances. It is possible to select a fraction of a post-performance documentation, search for corresponding images, and end up with a document from prior to human enactment. This demonstrates the extensive temporal span of performance works, beyond the moment of instantiation, and the way in which these things interweave ontologically. Alternatively we are able to select a section of a drawing and receive photos from performances - making explicit the dominant feature of shape in movement. However this process diminishes the significance of the human body and live instantiation. The work is embodied (made visual) through a computer. Whilst human movement has occurred in order to generate some of the sources, theses are equal to the sources which merely represent movement through drawing. Technology creates an interesting paradox: it is continually moving towards enhanced visualisation through dimensionality - the use of HD, 3D and motion capture technologies are 


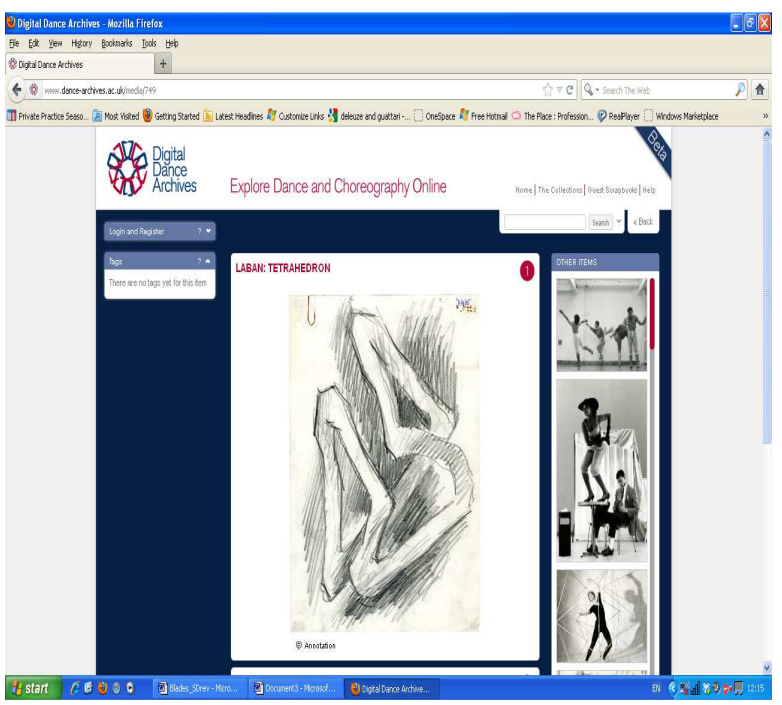

Figure 3: Example of one result from previous search

constantly finding new ways to take us closer to the 'reality' of three-dimensionality. For example, researchers at Ritsumeikan University in Japan are using motion capture to archive traditional Noa theatre and movement. (Hachimura 2006) This approach allows us to visualise the dimensionality of the body, however there is currently no escaping the flat nature of the screen. These enhanced dimensions are visualised through a 2D portal. Furthermore, the materiality of the body is decentralised. We traditionally searched archives through historical features, extraneous to the movement, such as the artist's name or the year of creation, however we are now able to search through the analysis of bodily form. This simultaneously draws us closer to the essence of movement, and further away, as the body becomes a two-dimensional, static image. Electronic visualisation removes the actual body from the center of focus and enquiry by prioritising the digtialised form.

\section{CONCLUSION}

Craig Hanks suggests that "for Heidegger technology is the supreme danger to man. The essence of technology, in the Heideggerian sense, presents a supreme danger because it prevents us from having a proper understanding of our own being, of our own essence." (Hanks, 2009). Heidegger suggests that technology makes nature a "standing - reserve" (Heidegger 1977). By this he means that nature becomes a resource to be called upon, or unlocked by technology. This is potentially an issue in relation to the systems I have discussed. Does the autonomous role of technology reduce the body to a standing reserve, therefore distorting dance's essential ontology? Heidegger claims that man cannot be a standing reserve, "Since man drives technology forward, he takes part in ordering and a way of revealing" (Heidegger 1977), because we are responsible for developing the technology, human beings cannot be seen as merely a standing reserve. However, can the body be considered distinct from the technologically driven man? The body is certainly re-situated within the spectrum of performative artifacts created by new software. The disembodiment of movement through visualisations of cognitive process demonstrates a chasm between the thought of movement and the actual event. Furthermore, the DDA demonstrates that, post-event, movement can once again be revealed as shape forms, distinct from the bodily act of moving. This means that the notion of embodiment - as involving the human body is challenged. We are able to see how movement can be created and made visual on a computer, and therefore embodied without the body.

The various images and documents created pre and post performance create a broader existential portfolio for works. We are able to see the way in which performances exist as images, from their inception in the imagination of the choreographer to their eternal representation in an archive. These images demonstrate the way in which works actually exist before and after performance, negating the ontological compulsion of liveness. The live performance is reduced to one event in a series of processes and experiences that we are now able to easily view and access. The way in which works exist as virtual entities, before and after physical existence in performance, raises philosophical problems concerning existence and reality, which are beyond the scope of this paper. However, whilst virtual existence has previously had no physical presence, technology has provided us with digital visualisations of this abstract mode of existence, by allowing for the documentation of process and product. This allows us to consider the reality of the virtual, and dispute the assumed importance of the actual.

Due to the way in which technology is being used in so many different ways by choreographers, we are faced with enormous multiplicity. This is problematic when discussing ontology. We cannot say that each way of using technology creates an ontologically distinct type of thing, as this would dispute the existence of an art-form labeled 'dance'. Dance works are types of the same thing, despite being made differently. We cannot claim that works made with the CLA, or stored on the DDA, are ontologically different to works made without digital technology, as this leads to vast and unmanageable subjectivity. Therefore, we must view these programmes as evidence of the way in which a work's ontology spans more than the moment of live performance. This understanding not only continues to challenge the significance of 
liveness as a defining ontological feature, but also disputes the primary importance of the human body, as the creation and consideration of works is focused towards shapes and images. We are able to understand these characteristics through visualisation, yet these methods do not necessarily re-configure dance, but rather re-configure our understanding of the form. This demonstrates Heidegger's observations of technology as a tool to reveal and help us understand the world.

\section{REFERENCES}

Auslander, P. (2008) Liveness: Performance in a Mediatized Culture. Routledge, USA, Canada.

Block, B., Kissel, J. (2001) The Dance: Essence of Embodiment. Theoretical Medicine and Bioethics, 22 (1), . 5-15.

Collingwood, R.G. (1958) The Principles of Art. Oxford University Press, Oxford, New York.

Cunningham, M. (1980) The Dancer and the Dance. Marion Boyars Inc. UK.

Concise Oxford English Dictionary. (2008) Oxford University Press, Oxford, UK.

DeLahunta, S, McGreggor, W and Blackwell, A.F. (2004) Transactables. Performance Research: On the Page, 9 (2), $67-72$.

DeLahunta, S. (2009) 'The Choreographic Language Agent' http://www.sdela.dds.nl/cla/ (retrieved 28 March 2012).

Dixon, S. (2007) Digital Performance. The MIT Press, UK, USA

Downie, M. (2009) Choreographic Language Agent [Online] http://openendedgroup.com/index.php/inprogress/choreographic-language-agent/ (retrieved 28 March 2012).

Forsythe, W. (2009) Synchronous Objects: For One Flat Thing, Reproduced] http://synchronousobjects.osu.edu/ (retrieved 28 March 2012).

Goodman, N. (1976) Languages of Art: An Approach to a Theory of Symbols. Hackett Publishing, USA.
Hachimura, K.(2006) Digital Archiving of Dance. Review of the National Centre for Digitization http://elib.mi.sanu.ac.rs/files/journals/ncd/8/ncd080 51.pdf (retrieved 28 March 2012).

Hanks, C. (ed). (2009) Technology and Values: Essential Readings. John Wiley \& Sons, USA.

Heidegger, M. (1977) A Question Concerning Technology And other Essays. Harper \& Row, USA.

Klemola, T. (1991) Dance and Embodiment. Ballet International, 1 (1),. 71-80.

Laban, R. and Ullman, L. (2011) The Mastery of Movement. Dance Books, UK.

Lamarque, P. (2010) Work and Object: Explorations in the Metaphysics of Art. Oxford University Press, Oxford, New York.

Levinson, J (1990) Music, Art and Metaphysics: Essays in Philosophical Aesthetics. Cornell University Press, USA.

McFee, G. (1992) Understanding Dance. Routledge, London, New York.

Open Ended Group. (2012) Field - Introduction . http://openendedgroup.com/field/OverviewBanners 2.html (retrieved 24.May 2012)

Phelan, P. (1993) Unmarked: The Politics of Performance. Routledge, London.

Royal Ballet (2012) http://www.roh.org.uk/about/bpbig-screens (retrieved xxx)

Royal Opera House. (2012) BP Summer Big Screens. http://www.roh.org.uk/about/bp-bigscreens (retrieved 24 May 2012)

Schiphorst, T. (1986) A Case Study of Merce Cunningham's use of the Lifeforms Computer Choreographic System in the Making of Trackers. http://www.sfu.ca/ tschipho/publications/Schiphorst M.A.Thesis.pdf (retrieved 28 March 2012).

Sheets-Johnston, M. (2011) The Primacy of Movement. John Benjamins Publishing Company, Amsterdam, Philadelphia.

Stelarc. (1980-2012) Stelarc Projects. http://stelarc.org/?catlD=20247 (retrieved 24 May 2012) 